\title{
RECLAMANDO SUS MISTERIOS: LA CONFERENCIA DE LA DIOSA IBÉRICA
}

\author{
Ma Cristina Perales Fernández \\ IES Antonio Domínguez Ortiz \\ Madrid
}

Recibido: 17/07/2012

Aceptado 08/10/2012

\section{Resumen}

España es un país en el que la tradición pagana ha tardado en arraigar. En los últimos 10 años, dos tradiciones han comenzado a tomar fuerza y a intentar visibilizar unas creencias más apegadas a la Tierra y en las que la figura de una divinidad femenina es primordial. Amparándose en los estudios históricos, mitológicos y antropológicos hechos en otros países, un grupo de personas iniciadas en las tradiciones Reclaiming y Avaloniana intentan traer de nuevo a la conciencia colectiva la creencia en la Diosa. Para ello han creado la Conferencia de la Diosa Ibérica en la intentan reproducir las experiencias religiosas que debieron ser comunes en Europa y en el mundo antes de la imposición del patriarcado.

Palabras clave: Tradición pagana, Conferencia de la Diosa, espiritualidad femenina, Femenino sagrado, religión de la Diosa, sacerdotisas.

\begin{abstract}
Spain is a country in which the pagan tradition has been slow to take root. In the past 10 years, two traditions have started to take hold and try to make visible their earth-based beliefs, in which the figure of a female divinity is central. Relying on the historical, mythological and anthropological studies in other countries, a group of person inciated in the Reclaiming and Avalonian tradition are trying to bring back to collective consciousness their belief in the Goddess. They have created the Conference of the Iberian Goddess in the attempt to reproduce the religious experiences that should be common in Europe and the world before the imposition of patriarchy.
\end{abstract}

Key words: Pagan Tradition, Goddess Conference, feminine spirituality, Sacred Feminine, Goddess religion, priestesses. 

El 24 de septiembre de 2010, durante la inauguración de la Primera Conferencia de la Diosa Ibérica, Kathy Jones dijo que estábamos ante el hecho religioso más importante que había ocurrido en estas tierras durante un par de milenios. En ese momento pensé que para ser inglesa era verdaderamente exagerada. Un par de años más tarde no puedo más que estar de acuerdo.

Durante el proceso de organización, ninguna de las personas implicadas fuimos conscientes de que, tal vez por primera vez desde el último cuarto del siglo $\mathrm{VI}^{1}$, estábamos celebrando abiertamente una divinidad pagana y ¡femenina!

\section{Antecedentes}

España, como de costumbre, llega tarde a los cambios culturales: nos pasó con el Renacimiento, con el Barroco y con el Neoclasicismo... ¿Por qué no habría de pasarnos también con el feminismo y sus diversas olas? En 1968, Monica Sjöö ya se había metido en problemas por pintar God giving birth. En 1979, en San Francisco, Starhawk estaba publicando su Danza en espiral ${ }^{2}$. Ese año el Estado Español firmada un concordato con la Santa Sede. Claramente, estábamos en otra onda.

Posiblemente me esté olvidando antecedentes fundamentales o tradiciones y corrientes paganas de importancia clave para entender el movimiento en la Península Ibérica, pero lo cierto es que a la organización de la Primera Conferencia de la Diosa Ibérica llegamos dos: la tradición Reclaiming y la tradición de Avalon.

La tradición Reclaiming es un tipo de brujería, moderna y feminista «surgida» a partir de las clases, talleres, campamentos y rituales públicos ofrecidos por Starhawk y Diane Baker desde 1978, al principio en el área de la Bahía de San Francisco, luego en el resto de los Estados Unidos y finalmente en Europa.

1. López Quiroga, Jorge y Martínez Tejera, Artemio M. «El destino de los templos paganos en Hispania durante la antigüedad tardía», Archivo Español de Arqveología, Vol. 79,págs. 125-153,2006

2. STARHAWK, La danza en espiral: un amor infinito, Barcelona, Obelisco, 2002.

Feminismo/s 20, diciembre 2012, pp. 205-221 
Es un sistema de creencias, una religión, además de un estilo ritual y mágico, pues sus miembros se definen (nos definimos) como brujas y brujos. Este sistema de creencias se resume en un texto conocido como los «Principios de Unidad $»^{3}$ que, básicamente propone lo siguiente:

- La Tierra es un ser vivo y toda forma de vida es sagrada y está interconectada.

- La Divinidad es inmanente, está presente en la Naturaleza (y en nuestro propio interior como parte de Ella).

- El respeto por la Naturaleza conlleva un compromiso con su protección y una implicación política activa.

- El reconocimiento de la Divinidad en nuestro propio interior y en el de cada persona determina que cada cual es su propia autoridad religiosa y no es necesario ningún intercesor, ni intérprete para relacionarnos con la Divinidad.

- El liderazgo es abierto e implica responsabilidad, no "poder sobre».

- La celebración de los ciclos naturales y personales lleva a la comprensión de que todo cambia, por lo que esta tradición se entiende como en permanente estado de evolución.

Esta tradición llega a España de manos de una alemana, Morgaine, en los años 90 del siglo pasado que empieza a formar Sacerdotisas y Sacerdotes (entendidos como facilitadoras y facilitadores de ceremonias, no como élite o jerarquía) de esta tradición a partir de 2005.

En cuanto a la tradición de Avalon, nace en Glastonbury, Inglaterra, de la mano de Kathy Jones. Es una tradición centrada en la Divinidad Femenina, a diferencia de la tradición Reclaiming. No es que no se reconozca lo Sagrado Masculino o que se niegue su existencia (de hecho, en la fiesta de Beltane, se celebra su presencia como Consorte de la Diosa). No se trata de darle una vuelta a la tortilla del monoteísmo patriarcal masculino: simplemente se trata de trabajar única y exclusivamente lo Femenino Divino como modo de devolver el equilibrio. Es una tradición menos orientada al activismo político o ambiental, aunque muchos de sus miembros estemos implicados en la ecología o la justicia social. La tradición de Avalon se presenta más como una escuela mistérica, como debió ser la de Eleusis y, por ello, su manifestación externa es más limitada.

Kathy Jones partió de sus intereses y formación previos. Por eso hay mucho de prácticas meditativas tomadas del budismo tibetano, así como de la

3. <http://www.reclaiming.org/about/directions/unity.html> consultado el 10-06-2012 
teatralidad del drama sagrado. Partiendo de ahí, del drama sagrado, con la intención de hacer participar a toda la comunidad de la experiencia de conexión con el misterio nace la Glastonbury Goddess Conference, nuestro principal referente a la hora de organizar la Conferencia de la Diosa Ibérica.

La primera Conferencia de la Diosa en Glastonbury tuvo lugar en 1995 y en 1998 Kathy Jones comenzó oficialmente su entrenamiento para Sacerdotisas y Sacerdotes de la Diosa y de Avalon.

Esta formación se estructura en tres espirales, tres años de trabajo, en los que se conoce, a través de la experiencia, la Rueda del Año y las Diosas de las Islas Británicas asociadas a cada momento del día, a cada estación o fase de la luna, a cada elemento, a cada etapa de la vida y las ceremonias con las que acompañar esos cambios.

La tradición de Avalon llegó por primera vez a España a través de una argentina, Sandra Román. Ella decidió formar Sacerdotes y Sacerdotisas de la Diosa en su tierra primero y en muchos países de habla hispana después. En América Latina investigó las antiguas divinidades femeninas precolombinas para construir con ellas una Rueda del Año sudamericana, la Chakana y empezó a iniciar a Sacerdotisas de la Cruz de Sur.

Para España diseñó la Rueda de Hisp-Anna, con divinidades autóctonas de España (Islas Canarias incluidas) y Portugal. Tuve el honor de formar parte de la primera promoción de Sacerdotisas de la Diosa Hisp-Anna en el Equinoccio de Otoño de 2007.

Como no podía ser de otro modo, estas dos tradiciones se encontraron en la Conferencia de la Diosa de Glastonbury de 2009 y sintieron la necesidad de «trasplantar» la experiencia en la Península Ibérica.

Pero ¿qué es una Conferencia de la Diosa?

\section{2. ¿Qué es una conferencia de la diosa?}

Aunque en castellano una conferencia suena a alguien hablando de un solo tema, en inglés «conference» significa «encuentro de gente con un interés compartido, especialmente si tiene lugar durante varios días». Tal vez hubiera sido una mejor traducción al castellano llamar a nuestro encuentro anual «Convención de la Diosa», pero no podíamos dejar de pensar en un montón de dentistas reunidos.

Además, etimológicamente, «conferencia» viene del verbo latino conferre que significa «llevar, reunir, entregar, ser útil». Y todo eso es lo que pretendemos con la Conferencia de la Diosa Ibérica: llevar a la sociedad española el concepto de lo Femenino Sagrado, reunir a quienes ya lo conocen (en mayor o menor medida) y entregarnos juntos a unas prácticas sagradas que no se 
conocían en estas tierras desde hacía milenios. Creemos que, con todo eso, somos útiles para la comunidad de la Diosa en particular y para la sociedad en general, contribuyendo a desmontar el patriarcado desde la instancia en la que surgió: la espiritualidad. Por otra parte, si el poder fáctico religioso en España se urde en la Conferencia Episcopal, nos parecía irreverentemente apropiado competir con un nombre que empezara con la misma palabra.

Así pues, una Conferencia de la Diosa es un encuentro anual en el que mujeres y hombres se reúnen para trabajar desde dentro la conexión con lo Sagrado Femenino. En este encuentro hay espacio para lo intelectual (a través de charlas o conferencias propiamente dichas en las que se abordan temas históricos, culturales y hasta políticos que tienen que ver con la Divinidad entendida como femenina), lo físico (mediante la práctica de disciplinas que conectan el cuerpo con la espiritualidad, como la biodanza, el yoga, el chikung...), lo artístico (con música, artesanía, danza...) y, como elemento especialmente diferenciador, hay un espacio para lo intrínsecamente espiritual, a través de la participación en ceremonias que intentan acercarse a lo que pudo ser el culto a la Gran Madre en los tiempos anteriores al patriarcado.

La Conferencia de la Diosa Ibérica es, de momento, la penúltima en surgir, pero sí que está siendo de las más persistentes. La pionera fue la Goddess Conference de Glastonbury que lleva celebrándose ininterrumpidamente desde 1995. Siguiendo la misma línea, han venido muchas más en otros países: en Astralia, Holanda, Argentina, Alemania, Suecia, Irlanda, Austria, Turquía... En 2012, México se une a la lista.

La Goddess Conference de Glastonbury ha sido el modelo, especialmente en lo ceremonial. Kathy Jones, su fundadora, es autora de numerosas obras de teatro sagrado, basadas en la mitología y, por ello, la puesta en escena es siempre muy visual y espectacular. La música, la iluminación, los trajes... consiguen trasladar a quienes participan a un tiempo remoto en el que el culto a la Diosa era lo habitual. Y lo más admirable es que consiguen hacerlo dentro de un espacio tan aséptico como la sala de usos múltiples del ayuntamiento de una pequeña ciudad británica (aunque últimamente se han ido expandiendo por espacios más sugerentes).

La Conferencia de la Diosa Ibérica también bebe mucho de las fuentes de los Witch Camp (o Campamentos de Brujas) de la tradición Reclaiming. Eso hace que cuestiones como la ecología y el compromiso político estén presentes. Igualmente, ha influido en el aumento del grado de participación de quienes asisten, especialmente en las ceremonias, y en el intento consciente de crear redes entre las personas, a través de grupos de afinidad, que hemos 
denominado «tribus», que se reúnen en momento claves para intercambias impresiones.

\section{La trastienda de los misterios}

Llevar a personas -generalmente urbanitas- del siglo XXI a experimentar emociones propias de las sociedades pre-agrarias precisa de cierto grado de intendencia.

En primer lugar, siempre tuvimos bastante claro que el Ayuntamiento de Madrid no nos cedería una de sus salas. Eso, en el fondo, fue lo mejor que nos podría haber pasado, ya que nos llevó a reflexionar sobre qué tipo de espacio queríamos usar. Finalmente, llegamos a la conclusión de que necesitábamos naturaleza a nuestro alrededor.

Discutir, debatir y reflexionar han sido buena parte de las labores de organización de las tres Conferencias de la Diosa que se han hecho en estas tierras. La del primer año fue especialmente dificultosa porque se juntaban cuatro nacionalidades (española, inglesa, alemana y argentina) y casi todo se hacía y escribía en dos idiomas (español e inglés). Ha sido todo un aprendizaje descubrir como se trabaja en círculo, llegando a todas las decisiones por consenso y no por mayoría, sin un líder designado, sino con diferentes personas que asumen responsabilidades. Para esta profesora de secundaria, acostumbrada a trabajar en el modelo jerárquico de la educación, esto ha sido todo un viaje.

Además de los espacios, había que organizar los viajes de las personas invitadas, sus alojamientos y hacer números, muchos números, porque nunca hemos contado con ningún tipo de subvención. Incluso tratar con la Policía Municipal para informar (que no para pedir permiso) de la celebración de una procesión pagana, con estandartes de la Diosa, que iba a tener lugar en Madrid por primera vez desde la fundación de la ciudad. Y no fue fácil hacer entender a las autoridades que no éramos una manifestación porque no estábamos protestando por nada, ni un espectáculo, sino un hecho religioso, como la Procesión del Silencio del Jueves Santo católico. No nos pusieron ningún tipo de trabas (aún no había nacido el 15M), de hecho creo que les daba completamente igual de qué tipo de actividad les estábamos informando, pero nos parecía importante dejar constancia de lo que estábamos haciendo porque era un hito y los hitos tienen que quedar marcados y bien marcados para las siguientes generaciones.

Los detalles de organización son simplemente una prueba de lo novedoso de esta experiencia: estábamos sacando a la Diosa del subconsciente más profundo de la población española y poniéndosela en medio de la Plaza de Cibeles en Madrid. 
La organización ha sido la capa externa. El contenido espiritual es la capa profunda: para devolver a lo Femenino Sagrado al centro de la vida religiosa hay que ir a nuestras raíces, al pasado, a lo que queda. Y cuando no queda ( $i y$ tantas veces no queda!), siempre se puede hacer arqueología-ficción.

La Diosas a las que se honró en la Península Ibérica nos inspiraron para reconstruir los misterios.

\section{Las máscaras de la Diosa}

En la tradición pagana de Avalon se trabaja con una rueda mitológica de nueve direcciones a las que se asocian los festivales solares, las fases lunares, los ciclos de la vida, nueve Diosas de las Islas Británicas y nueve «morgens» (que son unos seres míticos a medio camino entre las Diosas y las hadas, ligadas a la Naturaleza y que pervivieron en el ciclo de leyendas artúricas como las reinas hadas que conducen a Arturo a Avalon tras su derrota en la batalla de Camlann).

El modelo de rueda, círculo o espiral es especialmente importante dentro de los caminos espirituales paganos, neo-paganos o de algún modo conectados con la Tierra: reflejan la concepción del tiempo como cíclico, en el que nada es permanente excepto el cambio, pero en todo se repite de manera periódica, aunque nunca exactamente igual.

Kathy Jones estructura su rueda ${ }^{4}$ de tal modo que en los puntos cardinales se sitúan las Diosas «matronas» de los cuatro elementos y en los cuartos intermedios los arquetipos de Diosas que tienen que ver con las etapas de la vida.

Quedarían así:

- En el Noroeste se sitúa el arquetipo de la Diosa Doncella, cuyo festival (Imbolc) se celebra el 2 de febrero. Representa los nuevos comienzos, la inocencia y la renovación de la vida. En las Islas Británicas se la conoció como Brigit.

- En el Este encontramos a la Diosa del Fuego, que se celebra en la fiesta de Ostara (equinoccio de primavera). Representa el coraje, la pasión y la vitalidad. En Avalon la invocan como Artha.

- En el Sureste queda la Diosa Amante, que trae los dones de la sensualidad, la sexualidad y el goce. Su día sagrado es la fiesta de Beltane (1 de mayo) y se le asigna a la Diosa galesa Rhiannon.

4. JONES, Kathy, Priestess of Avalon, Priestess of the Goddess, Glastonbury, England, Ariadne Publications, 2006 
- El Sur es el lugar de la Diosa de las Aguas, Domnu. Ella es la regente de las emociones, de los recuerdos y de la intuición. Su festival se llama Litha y se corresponde con el solsticio de verano.

- Ker, la Diosa del grano y las cosechas pertenece al Suroeste. Es el arquetipo de la Diosa Madre y representa la abundancia, la nutrición y la protección. Su día sagrado es Lammas (1 de agosto)

- Banbha es una la Diosa irlandesa elegida para representar a la Madre de la Tierra. Ella nos invita a buscar la estabilidad, la manifestación y también la interiorización. Se la celebra durante la fiesta de Mabon (equinoccio de otoño) y se la sitúa en el Oeste.

- El arquetipo de la Anciana Sabia es en esta rueda la Diosa galesa Cerridwen. Ella representa el final, la muerte, la putrefacción. Su fiesta es Samhain, el 31 de octubre y su dirección, el Noroeste.

- El Norte representa el Aire, el espacio, el vacío cósmico, el sonido. La Diosa irlandesa Danu ocupa este lugar y su fiesta se celebra en el solsticio de invierno (Yule).

- El centro de la Rueda de las Islas Británicas lo ocupa una Diosa de reciente «re-creación»: Nolava, que es Avalon escrito al revés y a la que se dedican en su iniciación las Sacerdotisas de Avalon.

Basándonos en el trabajo de Kathy Jones, nuestra labor era descubrir los nombres y las historias de las Diosas que se habían honrado en la Península Ibérica y nos dimos cuenta de que apenas quedaba nada de nuestra mitología autóctona: la romanización asimiló las divinidades locales a las del Imperio y la cristianización posterior borró las pocas huellas que quedaban.

Contábamos con bibliografía muy exigua: poco más que un par de citas extraídas de aquí y de allá. Y, salvo en el caso de las Diosas de la mitología vasca, no se sabe nada de sus historias, sólo conjeturas de su «función». Así que aquí hubo de entrar la arqueología-ficción. En algún momento sentimos escrúpulos: ¿teníamos derecho a usar los nombres de esas antiguas Diosas en nuestras ceremonias, sin conocer exactamente quiénes habían sido? ¿No era eso mentir, inventar, engañar?

Lo cierto es que desde un punto de vista científico-histórico tradicional, justo eso sería lo que estamos haciendo. Pero jamás hemos pretendido escribir un libro de historia, ni afirmar que en el pasado las cosas eran justo tal y como nosotras las hemos intuido. Al rescatar los nombres de Divinidades

5. Ruiz Vega, Antonio, Los hijos de Túbal: Dioses y héroes de la Antigua España, La Esfera de los Libros, 2002; BlÁzQuez MARTínez, José María, Religiones, ritos y creencias de la Hispania Prerromana, Biblioteca Nueva, 2001. 
Femeninas honradas en la Península Ibérica sólo pretendemos que el pasado más remoto inspire el camino para un futuro en el que lo femenino no sea la mitad débil, infravalorada y maltratada de la sociedad. Creemos que hubo un tiempo en que las cualidades asociadas ahora la feminidad eran el modelo positivo y que bajo el auspicio de esos valores se desarrollaron las primeras sociedades. ¿Por qué no intentar de nuevo ese modelo, ahora que el de los últimos seis mil años ha dejado de funcionar?

Así que con nuestra pequeña lista de nombres con un par de rasgos asociados construimos nuestra propia rueda, la Rueda de Iberia, pues contenía Diosas tanto de España como de Portugal. Copiamos el modelo avaloniano de nueve direcciones (cuatro puntos cardinales, los cuatro intermedios y el centro) y distribuimos a las Divinidades Femeninas ateniéndonos a los rasgos que habían perdurado en el tiempo y, sobre todo, a nuestra intuición.

En ella conviven Diosas pancélticas, lusitanas, tartesias, fenicias, griegas, romanas, vascas... En definitiva, de todos los pueblos que han ido pasando por este fantástico portaviones entre continentes que es la Península Ibérica.

La Rueda ha ido evolucionando, cambiando Diosas de sitio o añadiendo alguna nueva, al ir encontrando más datos. Es otra de las ventajas de no pertenecer a un camino espiritual dogmático: esta flexibilidad que te permite modificar hasta lo más sagrado siguiendo tu propio criterio.

Por ello, lo que hoy aparece aquí podría estar completamente dado la vuelta de aquí a cinco años. Pero, por el momento, así queda la Rueda de Iberia:

NORTE - AIRE:

DIOSAS: Tanit, Mari.

ATRIBUTOS: Lo incorpóreo, lo que aún no se ha manifestado, lo esencial. FIESTA: Yule

NORESTE - DONCELLA:

DIOSAS: Belisama, Ilumberri, Chaxiraxi.

ATRIBUTOS: Creatividad, nuevos comienzos, inocencia, esperanza.

FIESTA: Imbolc

ESTE - FUEGO:

DIOSAS: Diana, Artemisa, Potnia Theron, Eguzki, Argia, Magek.

ATRIBUTOS: Coraje, valor, impulso, renacimiento, fuerza.

FIESTA: Ostara.

SURESTE - AMANTE:

DIOSAS: Venus, Afrodita, Potnia Hippon, Epona. 
ATRIBUTOS: Amor, pasión, sexualidad, sensualidad, placer sagrado.

FIESTA: Beltane.

SUR - AGUA:

DIOSAS: Noctiluca Nabia, Sirona.

ATRIBUTOS: Emociones, compasión, empatía.

FIESTA: Litha.

SUROESTE - MADRE:

DIOSAS: Cibeles, Juno, Rosmerta, Abuntia, Metragirta

ATRIBUTOS: Abundancia, nutrición, generosidad, agradecimiento, cosecha.

FIESTA: Lammas

OESTE - TIERRA:

DIOSAS: Ama Lur, Adartia, Hispania, Iberia, Hesperia.

ATRIBUTOS: Constancia, persistencia, manifestación.

FIESTA: Mabon.

NOROESTE - ANCIANA SABIA:

DIOSAS: Ataecina, Amandrea Illargui.

ATRIBUTOS: Muerte, descomposición, transformación.

FIESTA: Samhain.

CENTRO:

DIOSAS: Hispania, Iberia, Ophiusa.

ATRIBUTOS: Asimilación, tránsito, crisol.

FIESTA: Todos los días.

EL CORAZÓN DE LOS MISTERIOS

Los rostros difusos de estas Diosas son los aspectos de una feminidad sagrada, de unos roles femeninos positivos que queremos que vuelvan a estar vigentes en nuestra sociedad. Es un feminismo de lo interno, de lo inconsciente y no puede trabajarse sólo desde la palabra escrita o desde la acción directa.

Para mí este es un «feminismo del alma» (compatible con todos los feminismos anteriores, coetáneos y posteriores) que hay que ejercer desde la poesía, la danza y la música, con los sueños y los símbolos, con las connotaciones y los colores. A esa combinación, nos gusta llamarle «ceremonia»o «ritual».

En todas las Conferencias de la Diosa (Ibéricas y del mundo en general), las ceremonias son los huesos sobre los que se levanta toda la estructura. He asistido a unas cuantas y cada una es diferente, dependiendo de múltiples factores, el más importante de los cuales es el estilo personal de la persona o las personas que lo diseñen. 
De modo muy sucinto, se podría decir que en una ceremonia de nuestra tradición se rinde homenaje a un arquetipo divino que posee cualidades que consideramos positivas y que queremos despertar o potenciar en nuestras vidas.

Para ello, se toma la historia mitológica de esta divinidad (si existe y si no, se re-crea) y se eligen los detalles o pasajes más inspiradores. A partir de ellos, se crea una especie de drama sagrado en el que toda la comunidad interviene y lo actualiza, lo trae al presente.

Es difícil explicar en qué radica la diferencia con ver o intervenir en una obra de teatro. Lo que ocurre durante el tiempo en que se participa en una ceremonia no se analiza desde la mente analítica y racional, se experimenta con los sentidos y las emociones, con el lenguaje del subconsciente y del inconsciente colectivo.

\section{La primera conferencia de la Diosa Ibérica}

El primer año decidimos abordar el tema de la abundancia, en parte porque el arquetipo de la Diosa Madre es el más fácil de asimilar, ya que es el único que no estigmatizó el patriarcado. Sin embargo, no fue la única razón: la Conferencia se celebraba en Madrid, que es la única ciudad de Europa en cuyo corazón hay una imagen gigantesca de la Diosa y esa Diosa es Cibeles, la divinidad frigia de las cosechas, los cereales, la agricultura... Y, finalmente, durante los meses previos de preparación ya no se oía hablar más que de crisis económica. Considerábamos que una buena manera de alejarnos de esos pensamientos negativos sería invocar a su contrario natural.

Para nosotras, la crisis económica mundial era (jy es!) un efecto colateral del patriarcado y sus jerarquías: unos (por derecho divino, ley natural o lo que se quiera inventar) tiene acceso a los recursos naturales, a la fuerza de trabajo, a la circulación del dinero y otros (aunque más acuciantemente «otras») son privadas de su disfrute.

Así pues, durante meses, nos centramos en el desarrollo de ceremonias que despertaran las memorias de un tiempo en que la organización económica pudo ser distinta y, en cualquier caso, activar la certeza de que lo que ha sido no tiene por qué ser siempre igual.

Partiendo de los elementos de la Naturaleza, fuimos sanando los conceptos, las actitudes y emociones que nos impiden tener una vida abundante: esos conceptos tan judeo-cristianos de que lo material es moralmente peor que lo espiritual (y la materia se ha asociado siempre a lo femenino), que venimos a sufrir y a ganarnos el pan con el sudor de nuestra frente... E intentamos sustituirlo por las ideas del agradecimiento, la restauración del instinto 
animal de supervivencia como valor positivo, el orgullo sano que te hace sentir que mereces tener lo que deseas y la importancia de construir una comunidad igualitaria donde la generosidad y el cuidado primen sobre el egoísmo y el aprovechamiento.

Fue una conferencia tal vez más marcadamente política que las posteriores. Así, mi conferencia (y esta vez sí uso el termino con el sentido de «disertación en público) se llamó «Iluminar el pasado para alumbrar el futuro». En ella quemé una imagen del mito de Adán y Eva y otra de un troglodita arrastrando a «su hembra» por el pelo, para destruir simbólicamente la idea de que las mujeres hemos estado sometidas a los hombres desde el principio de los tiempos. Elegí estas imágenes para acabar con los dos frentes defensores de estas ideas, las religiones patriarcales y la ciencia que no ha incluido la perspectiva de lo femenino durante bastantes siglos. Después rendí homenaje a las académicas y estudiosas que han intentado aportarnos una visión distinta de cómo debió ser el pasado: Marija Gimbutas, Riane Eisler, Merlin Stone...

También el taller de Starhawk tuvo un marcado cariz político: entender la Naturaleza como fuente de abundancia puede ser una idea muy trasgresora en tiempos en los que sólo entendemos la prosperidad como el producto que se extrae de los cajeros automáticos. Entender los ciclos de nacimiento, crecimiento, reproducción, muerte y putrefacción, asimilarlos desde lo espiritual y desde lo político es una idea verdaderamente rompedora. Fue verdaderamente hermoso ver cómo un centenar de personas comenzábamos a encontrarle el cariz sagrado a las bacterias del hummus y el compost.

Llevo décadas gritando lo de «nosotras parimos, nosotras decidimos» y «sacad vuestros rosarios de nuestros ovarios», pero aquella mañana sentí que le daba la bofetada más decisiva a los dioses solares y apolíneos, a los ángeles sin sexo y a la cultura que desprecia lo terrestre y propone una huida a paraísos celestes que se alcanzan renunciando a nuestra verdadera naturaleza.

El punto final de la primera Conferencia de la Diosa también fue deliciosamente desobediente: habíamos informado a la policía y al Ayuntamiento de Madrid de que íbamos a organizar la primera procesión pagana de la historia de Madrid alrededor de la Fuente de Cibeles. Teníamos una hora y un recorrido asignados, pero como buena comunidad ecologista que somos, fuimos caminando y en transporte público y se nos hizo tarde.

Cuentan quienes sí llegaron a tiempo que había un par de furgonetas de la policía nacional (como suponíamos, procesión y pagana en la misma frase había sido demasiada información), pero cuando el grueso de la procesión llegó con los estandartes ya no había ningún tipo de vigilancia. Eso nos permitió 
pasearnos libremente con estandartes de Diosas de todas las culturas alrededor de la fuente.

No cortamos el tráfico en ningún momento: marchamos al ritmo impuesto por los semáforos, mientras los conductores tocaban sus bocinas, pensando tal vez que celebrábamos alguna victoria deportiva. Sólo un pequeño grupo de personas cruzó la isleta central para poner flores a la Diosa: no habíamos ganado ninguna copa, pero para la comunidad de la espiritualidad femenina en España este triunfo era mundial.

Como guinda del pastel, decidimos colgar los estandartes un momento en las verjas del Cuartel General del Ejército y tomarnos de las manos para bailar la danza en espiral, un baile de paz y celebración de la cosecha, justo frente a una de las instituciones que garantiza la continuidad del patriarcado.

Curiosamente, nadie vino a reprendernos, igual que nadie atropelló a quienes cruzaron el tráfico de la Glorieta de Cibeles. Yo, que soy una optimista patológica, decidí tomármelo como un buen augurio.

\section{La segunda conferencia de la Diosa Ibérica}

El segundo año decidimos afrontar el arquetipo «en espejo» del año anterior: si habíamos conocido a la Gran Madre, ahora queríamos dedicarnos a la Diosa Doncella, a la inocencia, a la creatividad, a la belleza...

Esperábamos (¡ilusas de nosotras!) que los preparativos prácticos serían más fáciles porque ya teníamos experiencia. Pero habíamos invocado a la Diosa de los nuevos comienzos y Ella nos contestó con su especialidad: tuvimos que hacerlo todo de nuevo otra vez.

En cuanto a lo mítico y espiritual, nos centramos en esta ocasión en los ritos de paso a la edad adulta. Por primera vez, decidimos separar a los participantes de las participantes en una ceremonia para que cada sexo pudiera celebrar tardíamente su cambio de fase vital. Esta decisión resulto algo polémica y algunos de los hombres nos hicieron ver que les parecía que caíamos en los errores del pasado, que (de algún modo) les estábamos segregando por falta de útero. Sin embargo, se trataba más bien de que las sacerdotisas no fuéramos capaces de diseñar una ceremonia en la que se incluyera el equivalente masculino a la primera menstruación, simplemente porque no lo habíamos experimentado. Así pues, dejamos la ceremonia masculina en manos de los sacerdotes de nuestra comunidad y nos centramos en revestir de valores positivos la menarquía, un momento que las más mayores habían sentido como vergonzoso o traumático y que a las jóvenes nos había hecho mirar con incomodidad, indiferencia o asco. 
Las mujeres del Teatro del Útero ${ }^{6}$ desnudaron sus cuerpos y sus experiencias ante la primera menstruación y se convirtieron en el reflejo de lo que las demás habíamos sentido. Podíamos haberlo vivido con mayor o menor angustia, pero lo cierto es que ninguna mujer de nuestra cultura vive su menarquia como una fiesta.

Así pues, la ceremonia de la Doncella Roja se dedicó en exclusiva a honrar el paso de la niña a la mujer y también a valorar nuestra feminidad que se renueva en ciclos. Intentamos sustituir los recuerdos desagradables sobre nuestra primera menstruación y todas las posteriores por una experiencia en la que la sangre femenina fuera reverenciada como un sacramento.

También dedicamos buena parte de la Conferencia a hablar de lo que significa ser «doncella» o «virgen» en los tiempos pre-patriarcales y -cómo no- de la Virgen María. Discutimos las implicaciones socio-políticas que tiene el enorme valor que se le ha concedido a la virginidad de las mujeres (nunca igualable a la de los hombres), ya que se trataba fundamentalmente de asegurarse de que el hijo primogénito (así, en masculino) de cada padre de familia fuera biológicamente suyo, pues era quien había de heredar las propiedades.

En los tiempos anteriores al patriarcado la herencia venía por línea materna, así que la sexualidad de las mujeres era mucho más libre, ahora la tacharían de promiscua. Así que el concepto de «doncella»o «virgen» en esos tiempos respondía al modelo de mujer joven e independiente, es decir, que ya no necesitaba a su madre para su subsistencia (como una niña), ni estaba dedicada al cuidado de sus propias criaturas. Así, en mi conferencia " ¡Ay, la Virgen!» intenté convencernos de que, independientemente de nuestra edad y estado civil, en nuestro interior habita siempre una doncella que no tiene que ser necesariamente casta.

\section{La tercera conferencia de la Diosa Ibérica}

Cuando este artículo se publique, ya habremos alcanzado simbólico número tres, que ya era sagrado para las gentes de la Diosa antes de que se lo apropiaran el padre, el hijo y el espíritu santo.

Las experiencias del año pasado nos llevaron a darnos cuenta de lo urgente que era trabajar con la sexualidad, con nuestros cuerpos y con nuestro derecho de nacimiento de acceder al placer. Por eso, esta vez nos dedicaremos al arquetipo de la Diosa Amante, que junto con la Anciana Sabia, ha sido el aspecto de la feminidad más reprimido por el patriarcado: está bien ser una

6. <http://teatrodelutero.blogspot.com.es/> consultado el 11-07-2012

Feminismo/s 20, diciembre 2012, pp. 205-221 
doncella casta y está bien ser una madre abnegada, pero las mujeres no pueden ser sexualmente activas, si no quieren ser consideradas unas putas.

Tanto hombre como mujeres hemos sufrido durante milenios de culpa por tener deseos, por sentir pasión y querer satisfacerla. Se nos ha hecho sentir impuros por no poder negarnos a una necesidad tan primaria como la de beber o respirar.

Por eso, en las ceremonias de este año queremos devolvernos el permiso a sentir placer, a darlo y a recibirlo, a sentirlo como algo bueno y sagrado y no como algo sucio y pecaminoso.

En uno de los textos más queridos del neopaganismo, «The Goddess Charge», atribuido a Doreen Valiente, se pone en la boca de la Diosa las siguientes palabras:

«Yo soy la belleza de la verde Tierra y la blanca Luna entre las Estrellas y los misterios de las Aguas. Yo llamo a tu alma para que se levante y venga a mí. Porque yo soy el alma de la Naturaleza que da vida al Universo.

De Mí procedes todas las cosas y a Mí deben retornar.

Que mi culto esté en corazón que se regocija, pues sabed que todos los actos de amor y placer son Mis rituales».

Inspiradas por estas palabras, la tercera Conferencia de la Diosa espera ser una celebración del placer heterosexual, homosexual, bisexual, pansexual... y de cualquier tipo que quede por aparecer o inventarse ${ }^{7}$.

\section{Conclusión}

El feminismo nos ha ido devolviendo a las mujeres, poco a poco, el control sobre parcelas de nuestra vida: el acceso al voto, al trabajo, al control de la riqueza y de nuestra fertilidad. Hemos recuperado nuestras mentes y nuestros cuerpos, pero nos queda el largo camino de recuperar nuestras almas.

Durante milenios se nos ha convencido de que un dios nos había hecho inferiores y así debía de continuar siendo. Nos lo han dicho con ritos en los que la figura central era siempre un hombre, oficiante, divinizado o profeta, en medio de nubes de incienso y música de letanías.

Por eso, a algunas nos ha resultado insuficiente convencernos desde lo mental de que no somos la mitad débil de la humanidad. Por eso, algunas sentimos la necesidad de descubrir, recuperar o inventar los misterios de la Diosa como el acto más radical de feminismo que se pueda imaginar. Eso es, ni más

7. A punto de cerrar este texto, he recibido la noticia de que ha sido imposible celebrar la tercera convocatoria de la Conferencia de la Diosa, consecuencia de la crisis económica (Nota de la coord.) 
ni menos la Conferencia de la Diosa, un feminismo de la raíz, que busca su fuerza en el pasado más remoto de la Humanidad.

\section{Referencias bibliográficas}

BlÁzQUez Martínez, José María, Religiones, ritos y creencias de la Hispania Prerromana, Biblioteca Nueva, 2001

JONES, Kathy, Priestess of Avalon, Priestess of the Goddess, Glastonbury, England, Ariadne Publications, 2006

López Quiroga, Jorge y Martínez Tejera, Artemio M. «El destino de los templos paganos en Hispania durante la antigüedad tardía», Archivo Español de Arqveología, Vol. 79,págs. 125-153,2006

Ruiz VegA, Antonio, Los hijos de Túbal: Dioses y héroes de la Antigua España, La Esfera de los Libros, 2002

STARHAWK, La danza en espiral: un amor infinito, Obelisco, 2002. 